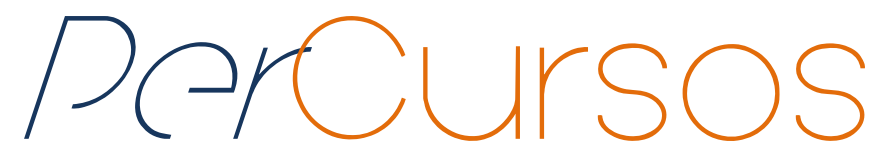

\title{
Com o coração na mão! A avaliação e autoavaliação na educação de jovens e adultos
}

\section{Resumo}

O presente artigo tem como proposta apresentar as representações dos alunos da Educação de Jovens e Adultos sobre avaliação e, a partir delas, discorrer sobre as contribuições de pesquisas e pontos que ainda precisam de avanços quando se trata da relação entre avaliação e processos de ensino e de aprendizagem na EJA. Para as reflexões aqui propostas, tomou-se como ponto de partida as percepções sobre avaliação de um grupo de vinte e três alunos do Ensino Fundamental e Médio de duas escolas que oferecem Educação de Jovens e Adultos na região da Grande Florianópolis, em Santa Catarina. A pesquisa que deu origem a este texto se caracteriza como qualitativa. Os estudos de Arroyo (2011), Oliveira (1999) e Freire (1999), bem como a verificação do estado da arte contemplado nas pesquisas de Haddad (2000), Rial (2007) e Carvalho (2009) forneceram suporte teórico e conceitual sobre o tema. A partir da análise dos dados, foi possível perceber que, por trás da preocupação com a avaliação, seus instrumentos e forma e sua relação com o processo de ensino e aprendizagem, se esconde um sentimento de uma trajetória escolar e pessoal permeada de fracassos e frustrações, mais do que de avanços e conquistas. O processo de autoavaliação é mais marcante que o próprio processo de avaliação.

Palavras-chave: Avaliação; Autoavaliação; Educação de jovens e adultos; Sujeitos da EJA; Representações de avaliação.

\section{Maria dos Anjos Lopes Viella Doutora em Educação pela} Universidade Federal de Santa Catarina - UFSC. Professora do Instituto Federal de Educação, Ciência e Tecnologia de Santa Catarina - IFSC. Brasil

maria.viella@ifsc.edu.br

\section{Marizete Bortolanza Spessatto}

Doutora em Educação pela Universidade Federal de Santa Catarina - UFSC. Professora do Instituto Federal de Educação, Ciência e Tecnologia de Santa Catarina - IFSC. Brasil

marizete.spessatto@ifsc.edu.br

\section{Pamela de Almeida}

Licenciada em Ciências da Natureza pelo Instituto Federal de Educação, Ciência e Tecnologia de Santa Catarina - IFSC. Professora do Centro Educacional de

Barreiros e Escola Paulo Freire. Brasil

pameladealmeida19@hotmail.com 


\title{
On tenterhooks! Evaluation and self-evaluation in youth and adult education
}

\begin{abstract}
This article aims to present the representations of Youth and Adult Education students on evaluation and, from them, discuss points that still need improvements when it comes to the relation between evaluation, selfevaluation and teaching and learning processes at YAE. To the reflections proposed here, it was taken as a starting point the perceptions about evaluation of a twenty three student group from Middle and High School in two schools offering Youth and Adult Education at the Great Florianópolis area, Santa Catarina. The research that led to this text is characterized as qualitative. Studies of Arroyo (2011), Oliveira (1999) and Freire (1999), as well as the verification of the state of the art contemplated in research from Haddad (2000), Rial (2007) and Carvalho (2009) provided theoretical and conceptual support about the theme. From the data analysis, it was realized that behind the concern with the evaluation, their instruments, ways and relations with the process of teaching and learning, hides a feeling of a personal and school career filled with failures and frustrations, more than advances and achievements. The self-evaluation process is most striking than the evaluation process itself.
\end{abstract}

Keywords: Evaluation; Self-evaluation; Youth and adult education; YAE subjects; Representations of evaluation.

\section{Para citar este artigo:}

VIELLA, Maria dos Anjos Lopes; SPESSATTO, Marizete Bortolanza; ALMEIDA, Pamela de. Com o coração na mão! A avaliação e autoavaliação na educação de jovens e adultos. Revista PerCursos. Florianópolis, v. 16, n.31, p. 06 - 27, maio/ago. 2015.

\section{DOI: 10.5965/1984724616312015006}

http://dx.doi.org/10.5965/1984724616312015006 


\section{Nos caminhos da pesquisa: a avaliação e os sujeitos da EJA}

Por mais que as discussões sobre avaliação tenham avançado nos últimos anos nas escolas, muitos alunos ainda ficam com o coração na mão diante de processos avaliativos. Nessa direção, Arroyo (2014) oferece rara contribuição quando sugere algumas indagações sobre esses sujeitos. Que sentimentos e percepções desses sujeitos permeiam esse processo? Que categorias de pensamento expressam essa realidade da avaliação, explicando-a, justificando-a ou questionando-a? Como se pensam e se veem enquanto sujeitos? Como são pensados e vistos?

Apesar de muitas instituições terem um discurso inovador sobre o tema (incorporado e difundido por documentos oficiais, inclusive), são raras as exceções em que os processos avaliativos vão além de provas e atribuições de médias bimestrais ou trimestrais. É preciso refletir sobre a avaliação para além da sala de aula, para outros âmbitos avaliatórios, pois é também nesses outros âmbitos que vai se consolidando um processo de autoavaliação. Assim, faz-se necessária uma formação docente que dialogue com esses outros espaços em que se dá a sociabilidade dos estudantes da EJA dimensionando seu peso na autoavaliação. Algumas questões fundamentais precisam ser consideradas: Quem são esses sujeitos? Em que labirintos da vida trafegam? Quais as possibilidades de encontrarem uma porta de saída? É nesse contexto que se revela um processo de autoavaliação muito mais significativo do que propriamente a avaliação que acontece na escola.

Este artigo resulta de uma pesquisa realizada em outubro de 2013, em duas escolas da rede pública de Florianópolis, participando 23 estudantes, na faixa etária entre quinze e vinte e dois anos e contando com dois estudantes com mais de 40 anos. Uma alternativa metodológica utilizada para alcançarmos os objetivos das reflexões aqui propostas foi solicitar aos alunos a escrita de suas memórias, sendo para isto distribuída uma folha de papel com orientações para escrita da autobiografia, sugerindo relatos de fatos que marcaram a história de vida pessoal e profissional, os acertos e desacertos, as vitórias, deixando a liberdade de ser produzido um texto escrito ou também utilizando outras linguagens, como imagens, fotografias, documentos e/ou desenhos. Foi solicitado 
ainda que o texto contemplasse dados sobre o seu local de origem, idade, experiências profissionais, pessoais, acadêmicas e formativas. Na produção, buscou-se captar aspectos significativos de sua história de vida, tais como trajetórias pessoais, profissionais e escolares, foco de nossa análise.

Como última estratégia de coleta de dados, foi solicitado aos alunos que fizessem um desenho ou escrevessem uma breve frase que representasse o sentimento deles em relação à avaliação para analisar as concepções de avaliação que carregam, como a representam e, a partir desses dados, refletir sobre algumas propostas avaliativas para a EJA. Acredita-se que, a partir dessas percepções, seja possível melhor compreender o processo de avaliação, considerando as especificidades do público que frequenta a EJA e, sugerir alternativas para processos avaliativos que levem em consideração as diferenças que constituem os sujeitos de um mesmo nível escolar ou de uma mesma sala de aula.

Como coloca Sordi (2010, p. 25), há um discurso progressista sobre a avaliação que não se revela presente nas formas de avaliação praticadas e que tendem a não se afastar do viés classificatório, excludente e disciplinador. A situação se torna ainda mais complexa quando se trata da Educação de Jovens e Adultos, como é o caso da afirmação que dá título a este artigo, produzida por uma estudante da EJA, quando solicitada a descrever seus sentimentos diante das avaliações escolares ${ }^{1}$.

Os sujeitos, apesar de todas as especificidades que os constituem, muitas vezes têm suas trajetórias escolares e de vida ignoradas nos processos de ensino e de aprendizagem e, dessa forma, também nos processos avaliativos. Mas essa não é uma rua de mão única. Minayo (2008, p. 98) ao mostrar, recorrendo a Marx, que "as representações, as ideias e os pensamentos são o conteúdo da consciência, que por sua vez, é determinada pela base material”, aponta também, com base nesse mesmo autor, a forma como as ideias estão comprometidas com as condições de classe, e afirma que "as circunstâncias fazem os homens, mas os homens fazem as circunstâncias" (MINAYO, p.

\footnotetext{
${ }^{1}$ Quando solicitados a expressarem em um desenho os sentimentos que os processos avaliativos lhes suscitam, dois estudantes utilizaram o desenho do coração para expressar a ideia. Um deles, além do desenho, inseriu a frase "Fico com o coração na mão". Outro desenhou-se segurando um coração em uma das mãos.
} 
99). São esses sujeitos que chegam às escolas trazendo consigo as marcas das vivências de segregação.

O público adulto da EJA, afirma Oliveira (1999), não pode ser classificado como outros públicos adultos em processo de escolarização. A autora salienta que:

[...] no âmbito da educação de jovens e adultos, não é o estudante universitário, o profissional qualificado que freqüenta cursos de formação continuada ou de especialização, ou a pessoa adulta interessada em aperfeiçoar seus conhecimentos em áreas como artes, línguas estrangeiras ou música, por exemplo. Ele é geralmente o migrante que chega às grandes metrópoles proveniente de áreas rurais empobrecidas, filho de trabalhadores rurais não qualificados e com baixo nível de instrução escolar. (OLIVEIRA, 1999, p. 59)

Ainda, reforça Oliveira (1999), é fundamental considerar o fato de que esse adulto também é um excluído da escola, a ela incorporado tardiamente em busca da conclusão do ensino fundamental ou médio. Sendo assim, destacam Fernandes e Viana (2009, p. 314), o educador precisa observar os diferentes ritmos, comportamentos, experiências, relações pessoais, familiares, para que suas intervenções pedagógicas garantam como fator essencial o respeito à heterogeneidade. E isso faz com que o aluno se sinta sujeito de sua aprendizagem, tenha mais interesse e reduza as chances de evasão da escola.

\section{A avaliação na educação de jovens e adultos como campo de pesquisa}

A fim de termos um panorama das pesquisas sobre o tema aqui proposto, foi utilizado o estudo do estado da arte das pesquisas em EJA no Brasil, de 1986 a 1998 (HADDAD, 2000); estado da arte sobre PROEJA de 2007 a 2011 (VIANA, 2011); estado da arte sobre avaliação da aprendizagem na EJA, considerando teses e dissertações do banco da CAPES, de 1987 a 2006 e ainda trabalhos e pôsteres aprovados para o GT 18 (Educação de Pessoas Jovens e Adultas) da ANPEd - Associação Nacional de PósGraduação e Pesquisa em Educação, referentes ao período de 2000 a 2006, da $23^{\mathrm{a}}$ à $29^{\mathrm{a}}$ Reuniões Anuais (RIAL, 2007). Foi ainda analisada uma pesquisa denominada Estado da 
Arte, de Oliveira, Dias e Mota Neto (2012) que apresenta um mapeamento de teses e dissertações sobre EJA que tem como principal referência teórica o pensamento educacional de Paulo Freire. As pesquisas nessa perspectiva, de acordo com Ferreira (2002), são definidas como de caráter bibliográfico, trazem em comum o desafio de mapear e de discutir uma certa produção acadêmica em diferentes campos do conhecimento, tentam responder que aspectos e dimensões vêm sendo destacados e privilegiados em diferentes épocas e lugares e são reconhecidas por utilizarem uma metodologia de caráter inventariante e descritivo da produção acadêmica e científica sobre o tema que busca investigar (FERREIRA, 2002, p. 258).

O trabalho de Haddad (2000) é fundamental para a análise do tema, pois ele atualiza os estudos que compuseram um estado da arte da educação de jovens e adultos no Brasil de $1986-98^{2}$, com o período de $1975-85^{3}$, cobrindo um período de 23 anos de pesquisa sobre essa temática. Ele define os estudos de tipo estado da arte, como aqueles que "permitem, num recorte temporal definido, sistematizar um determinado campo de conhecimento, reconhecer os principais resultados da investigação, identificar temáticas e abordagens dominantes e emergentes, bem como lacunas e campos inexplorados abertos à pesquisa futura" (HADDAD, 2000, p. 4).

Para analisar os dados, utilizou-se a análise de conteúdo. Segundo Franco (2003, p. 13):

O ponto de partida da Análise de Conteúdo é a mensagem, seja ela verbal (oral ou escrita), gestual, silenciosa, figurativa, documental ou diretamente provocada. Necessariamente, ela expressa um significado e um sentido. Sentido que não pode ser considerado um ato isolado.

\footnotetext{
${ }^{2}$ O levantamento, inicialmente, foi extensivo, compreendendo não só a produção acadêmica stricto sensu, mas toda sorte de publicações, inclusive documentos de órgãos públicos de educação e de organizações não governamentais (ONGs). Esse levantamento das ONGs corresponde à primeira etapa de um dos subprojetos integrados à pesquisa Juventude e Escolarização: uma análise da produção de conhecimentos, coordenada pelos Profs. Drs. Marília Pontes Sposito e Sérgio Haddad, envolvendo a Faculdade de Educação da Universidade de São Paulo (FEUSP), a Pontifícia Universidade Católica de São Paulo (PUC/SP) e a Ação Educativa - Assessoria, Pesquisa e Informação, com o apoio do CNPq e a FAPESP (HADDAD, 2000, p. 5-6).

${ }^{3}$ Esse período também resultou em várias publicações sobre o Estado da Arte sobre o ensino supletivo no Brasil.
} 
Para melhor compreender os termos estado da arte, ou estado do conhecimento, recorreu-se a Romanowski e Ens apud Laffin (2014):

\begin{abstract}
[...] para realizar um "estado da arte" (...) não basta apenas estudar os resumos de dissertações e tese, são necessários estudos sobre as produções e congressos na área, estudos sobre as publicações em periódicos na área. O estudo que aborda apenas um setor das publicações sobre o tema estudado vem sendo denominado de "estado do conhecimento".
\end{abstract}

Nas pesquisas denominadas Estado da arte em Educação aqui analisadas, a temática avaliação na EJA não é recorrente. No quadro dos temas e subtemas apresentados por Haddad (2000, p. 10) a avaliação não aparece. Rial (2007, p. 05) também fez um levantamento dos trabalhos publicados no Banco de Teses da Capes entre 1987 e 2006 e, nessa pesquisa, ela encontrou cinco dissertações referentes à avaliação na EJA. Para concluir o estudo, Rial (2007) também pesquisou trabalhos e pôsteres no GT18 da Anped, publicados entre 2000 e 2006, porém não encontrou nenhum trabalho referente à avaliação na EJA. Carvalho (2009), assim como Rial (2007), também analisou as teses e dissertações no período de 1987 a 2006 no Banco de teses da CAPES e verificou que, mesmo que a avaliação apareça pouco, houve um aumento significativo nas produções acadêmicas sobre EJA a partir dos anos 2000, pois foi a partir desse ano que a modalidade teve um espaço maior nas reflexões educacionais, com a promulgação do parecer sobre as Diretrizes Curriculares Nacionais da EJA.

Carvalho (2009, p. 120) construiu um quadro referente ao número de publicações sobre EJA entre 1987 e 2006. Dentro desse período, a região Sul publicou 121 dissertações e 13 teses, sendo Santa Catarina responsável por apenas uma tese e 21 dissertações sobre a temática Educação de Jovens e Adultos.

Ao analisar os temas recorrentes em cada trabalho, Carvalho (2009, p. 124) construiu um gráfico com as temáticas alfabetização, formação de professores, políticas públicas, disciplinas específicas, exclusão/evasão/inclusão, sujeitos, ensino noturno e 
trabalho, educação carcerária e educação a distância, não aparecendo a avaliação entre os temas em estudo.

Viana (2012, p. 50) traça um panorama da produção acadêmica, representada pelas 29 dissertações de mestrado e três teses de doutorado, desenvolvidas pelos discentes dos cursos de pós-graduação stricto sensu em Educação da FaE-UFMG e do mestrado em Educação Tecnológica do CEFET-MG, entre janeiro de 2007 e março de 2011, que trataram de temáticas relacionadas à Educação Profissional Integrada à EJA e foram orientadas por professores participantes da equipe do Projeto 008/PROEJA/CAPES/SETEC. Ao classificar essa produção segundo as seis áreas temáticas definidas pelo Projeto, a avaliação na EJA também não comparece.

Olhando especificamente para as pesquisas sobre o estado do conhecimento no campo da Educação de Jovens e Adultos (EJA) no e do Estado de Santa Catarina, temos o trabalho de Laffin (2014), cujos dados foram retirados do Banco de teses da Capes, entre 2002 a 2012 e dentre os objetos de pesquisa achados pela autora, a avaliação na EJA não está contemplada.

Como forma de verificar se ainda não há publicações sobre avaliação na EJA, também foi realizado um levantamento na Anped dos temas dos trabalhos e pôsteres apresentados no GT18 (Educação de Jovens e Adultos). O levantamento foi feito a partir da $30^{\mathrm{a}}$ reunião até a $36^{\mathrm{a}}$ reunião, compreendendo os anos de 2007 a 2013. Esse período foi escolhido para complementar o período analisado por Rial. Foram localizadas várias produções sobre a EJA, contudo a atenção estava voltada para títulos nos quais não constava a temática avaliação na EJA. Como apontam os dados indicados no trabalho de Rial (2007), não há publicações sobre este tema na Anped. O único trabalho referente à temática avaliação foi um pôster apresentado na 30ª reunião, em 2007 cuja autoria é da própria Rial.

Sendo a avaliação um tema tão polêmico e atual, há de se indagar o porquê desse silenciamento das pesquisas sobre a avaliação na EJA e, ao mesmo tempo, deixar falar os sujeitos que frequentam essa modalidade de ensino. Deve-se questionar: Quem é ele? Qual a idade? Onde trabalha? Qual seu objetivo na EJA? Por que retorna à escola? 


\section{Aproximando-se dos sujeitos da EJA}

Como já explicitado, essas reflexões tomam como base a percepção sobre avaliação dos sujeitos de duas escolas localizadas na região da grande Florianópolis, em Santa Catarina. Nas escolas pesquisadas, dez estudantes estão na faixa etária de 15 a 18 anos, cinco têm entre 20 e 25 anos, um está na faixa de 26 a 30 anos e dois tem mais de 30 anos; outros cinco estudantes não preencheram o campo faixa etária, em questionário aplicado ao grupo. Os dados coletados reforçam o que as pesquisas têm mostrado; que houve um rejuvenescimento da população que cursa a Educação de Jovens e Adultos, sendo o público constituído por estudantes de 15 a 18 anos em maioria na sala de aula.

Com relação à questão de gênero, homens e mulheres estão em números praticamente iguais, sendo oito homens e cinco mulheres na turma de nono ano (com total de 13 alunos). Cinco homens e cinco mulheres constituíram a turma de primeiro ano do ensino médio pesquisada. Esses educandos são filhos/pais/mães; homens/mulheres; empregados/desempregados/patrões. São várias as condições presentes em uma sala de aula. A partir das autobiografias foi possível conhecer um pouco de cada sujeito, com informações sobre a família, o trabalho, a escola etc.

Em relação ao trabalho, alguns estudantes ${ }^{4}$ mencionam as atividades que exercem: doméstica (Aline), marceneiro (Élcio), função acumulada de pintor e garçom (Lucas), encarregado de manutenção de máquinas e aparelhos (Marcos, Allan), função acumulada de garçonete e manicure (Ísis), empregado de empresa de ar-condicionado (Antonio), auxiliar de produção (Fabiana), telemarketing (Júlio); outros se dizem "apenas estudantes" (Marisa, Cátia e Tiago). Outras vezes o trabalho não é mencionado na autobiografia (Douglas, Telma, Joel, Leonardo e Graciele).

Embora alguns revelem aspectos da centralidade do trabalho e do estudo na sua vida, muitas vezes isso aparece de forma contraditória: “comecei a estudar de novo para conseguir trabalho melhor" (Túlio); "Não trabalho, mas queria" (Carla); “Eu também trabalhava, mas saí. Agora eu estou correndo atrás do 'preju'." (Walter); "Fiz até a oitava série e desisti ... comecei a trabalhar, depois saí do serviço porque era no comércio... depois

\footnotetext{
${ }^{4}$ Os nomes aqui apresentados são fictícios.
} 
comecei a trabalhar novamente, mas engravidei na experiência e fui mandada embora." (Cátia); a impossibilidade de conciliar "escola e trabalho", pois "meu horário de estudar, não batia com o horário de serviço" (Neusa e Túlio). Alguns ainda disseram estar "à procura de serviço" (Luísa).

É essa diversidade de sujeitos que compõe o público da EJA e todas as vivências que os constituem precisam ser consideradas quando se pensa em ensinar, aprender e avaliar. Segundo a VI CONFITEA (BRASIL, 2009), pensar sujeitos da EJA é trabalhar para, com e na diversidade. Por isso, a grande importância de conhecer os alunos com os quais se trabalha. É conhecendo suas histórias de vida e seus perfis que a ação pedagógica será mais efetiva. Com uma simples atitude, pode-se conhecer uma parte muito importante e crucial da vida do aluno e isso pode influenciar a prática docente.

Como também reforçam os dados coletados para a realização deste trabalho, os sujeitos da EJA possuem idades diferentes, experiências de vida diferentes e retornaram aos bancos escolares por motivos diferentes. Ribeiro (2002) cita mais algumas razões: o sonho de conquistar melhores salários, a ameaça do desemprego, a necessidade de contribuir mais eficazmente na formação dos filhos, a realização pessoal, entre outras.

Várias falas extraídas das autobiografias revelam muito sobre os percursos de vida dos estudantes e os seus objetivos com o retorno à escola: melhorar as condições de vida, sobretudo as condições econômicas. A conquista de um diploma de conclusão do ensino médio pode assegurar, acreditam, o acesso a um emprego melhor (Túlio) e a uma faculdade ou curso técnico (Carla, Tiago, Gustavo, Marcos, Élcio, Telma, Cátia) ou mesmo outro rumo na vida (Lucas), pois "sem estudo não se vai muito longe” (Fabiana); "Espero aguentar até o final [da EJA]. Pretendo me formar em delegada." (Telma).

Revelam, ainda, por que saíram da escola, como veem a EJA e como se veem: “Minha família são todos de bem" (Walter); "Com quinze anos tive o meu primeiro filho. Estava na $6^{a}$ série. Quando ele completou seis meses voltei a estudar, mas em colégio regular. Fiz até a metade da $8^{a}$ série e desisti" (Cátia); "Acordo às 5 h30 da manhã e vou trabalhar e saio de lá às $18 \mathrm{~h}$ e vou para a escola e eu tô fazendo o supletivo para terminar o colégio mais rápido." (Gustavo); "Sempre tive bom êxitos com as avaliações e não tem 
muita diferença das avaliações de ontem para as de agora" (Joel); "Gosto de estudar, aprender, desenvolver o cérebro [...]. Gosto do método de ensino da EJA" (Fabiana). Para além desses, um depoimento chama a atenção, diferenciação estabelecida pela estudante entre a EJA e o ensino regular:

Saí do regular porque repeti $01^{\circ}$ ano e vim pra EJA porque era a escola mais perto da minha casa. Eu, na real, não queria estar na EJA, queria ficar no regular pra ganhar meu diploma como verdade, não um diploma incompleto. No ensino fundamental e no regular, sempre ficava em prova final [...].Tinha dificuldade em Matemática e Português. (Luisa)

Quando da apresentação dos motivos que levaram esses jovens e adultos a abandonarem os estudos, apenas seis alunos, dos 23 que escreveram a autobiografia, falam sobre a sua saída da escola. Entretanto, mais do que dar ênfase à saída, eles relatam com entusiasmo a volta aos bancos escolares:"Parei de estudar para ajudar em casa" (Marcos); "Graças a Deus consegui [voltar a estudar] e agora vou trilhar outro caminho, o caminho do conhecimento" (Lucas).

É bom destacar a forma como aparece na fala desses sujeitos a apreciação positiva sobre o trabalho dos professores: "Quero recuperar o tempo perdido, mas ir além eu sei que é difícil, mas com fé e claro com a ajuda de alguns anjos que nesse caso são os professores que são muito legais e compreensivos." (Lucas); "Os professores ajudam bastante, ensinam bem" (Tiago, Élcio e Telma).

No terceiro bloco de questões apresentadas, os alunos comentaram sobre os seus objetivos ao retornarem para a EJA. Falaram de seus sonhos e desejos, estando entre eles a intenção de dar bons exemplos aos filhos. Além disso, esses jovens e adultos não querem apenas os diplomas de ensino médio, querem ir além, sonham com a conclusão do ensino superior: "Estou estudando porque gostaria de melhorar dentro da empresa e quem sabe até fazer faculdade de Administração ou Direito" (Marcos). "Entrar em uma universidade para Ciências Contábeis” (Ísis); “Agora que já realizei alguns sonhos como carro, moto e casa própria, decidi dar outro rumo à minha vida através da EJA" (Lucas); “Optei pela EJA porque tenho que correr atrás do tempo perdido, parei de estudar em 2008, 
e também percebi que sem estudo não se vai muito longe. Tenho dois filhos e quero ser um exemplo pra eles, dar condições de vida melhor a eles" (Fabiana); "Pretendo terminar meus estudos e fazer faculdade de medicina" (Graciele); "Pretendo me formar em delegada" (Telma); "Pretendo terminar todo o ensino médio e fazer cursos, ainda não sei para quê, mas gosto bastante de enfermagem" (Cátia).

No quarto conjunto, estão algumas informações pessoais de situações que marcaram suas vidas, especialmente os sofrimentos ao longo da vida, as separações, as perdas etc: "Comecei a namorar bem cedo com meu marido aos 13 anos e aos 15 anos tive meu primeiro filho. Estava na $6^{a}$ série" (Cátia); “Me separei há dois anos, minha vida passou muito rápido, lembranças ruins do meu passado que nunca vou esquecer" (Aline); "Fatos que marcaram a minha vida este ano foram deixar de ser evangélico e sair do meu trabalho" (Túlio); "Não tenho namorado porque ainda não achei um ou pelo fato de eu não querer, mas tenho várias amizades coloridas. No futuro vou morar com minha tia nos EUA" (Carla); “Eu sou gay e ser gay não é opção, é condição" (Douglas).

Esses são os sujeitos da pesquisa com seus anseios e sonhos. A escola faz parte de um desses sonhos, mas será que as pessoas que voltam à escola cabem nesses espaços? O sistema escolar foi feito para elas? Arroyo (2011, p. 223) comenta em seu texto a fala de uma professora: "sempre tivemos adolescentes e jovens no ensino fundamental e médio, mas eram outros". Sendo assim, reconhecer essa realidade nos situa em um caminho promissor para acertar nas posturas profissionais. Se eles e elas são outros, nós teremos que ser outros profissionais.

Segundo Arroyo (2011, p. 226), se os alunos são outros, não é possível incorporálos nos tradicionais processos pedagógicos, docentes, de ensino-aprendizagem, nos currículos, nas metodologias e nas avaliações. Logo, precisamos de outro sistema, outros ordenamentos, outras didáticas e até outra formação profissional.

Se tomarmos como base os depoimentos aqui apresentados, não é o bastante atrair os alunos para a escola: é preciso garantir que eles não abandonem os estudos, os seus sonhos e desejos profissionais e pessoais. E isso é um grande desafio para o professor, pois o espaço da sala de aula é o ambiente da heterogeneidade. Cabe a cada 
educador investigar desejos e dificuldades de cada um para, então, refletir sobre o processo de ensino e de aprendizagem e a partir dele a avaliação.

\section{A avaliação e a autoavaliação na perspectiva dos alunos da EJA}

A avaliação realizada nas escolas brasileiras está centrada, via de regra, no desempenho quantitativo dos alunos, geralmente por meio de aplicação de provas. Os alunos estão tão acostumados com essa forma de avaliação que o desenvolvimento das atividades propostas normalmente está atrelado ao fato de "valer nota". Em muitos casos, a prova, ao invés de ser vista como um instrumento de aferição da aprendizagem, transforma-se em castigo. Quem nunca ouviu ameaças como: “se não se comportarem, terá prova na próxima aula"! Revela-se, assim, uma relação de poder do professor, na qual a prova é a punição.

Afinal, como se apresenta a avaliação na EJA? Que caminhos ela segue? Considerar as representações dos alunos sobre a avaliação supõe considerá-las como "imagens construídas sobre o real [...] mesmo sabendo que ela traduz um pensamento fragmentário e se limita a certos aspectos da experiência existencial, frequentemente contraditória, possui graus diversos de claridade e de nitidez em relação à realidade" (MINAYO, 2008, p. 108).

Nas escolas observadas, embora a avaliação cause certo estado de desespero e nervosismo nos estudantes, ela segue outra direção. A diferença destacada por eles é de que a maioria dos professores faz as provas permitindo a consulta no caderno - como uma forma de "ajudar" o aluno, mas sem deixar as exigências de aprendizagem em segundo plano. Essas mesmas exigências são colocadas por eles, como experiências avaliativas que contribuem para a aprendizagem conforme vem destacado no depoimento a seguir, sobre a forma como a avaliação vem sendo realizada:

Essa avaliação eu achei legal, diferente, porque quando voltamos a estudar de novo, muitas coisas vem na cabeça e (a gente) pensa: vai ser difícil, porque aula quer dizer, para todos é prova, trabalho... e muitos que já deixaram de estudar não tem tempo para estudar e fazer trabalhos 
escolares. Eu prefiro um debate, um resumo [...] porque para resumir tenho que ler com atenção, às vezes, várias vezes uma parte do texto, assim eu aprendo no tempo da aula, sem levar assuntos para casa. Assim eu arranjo tempo para estudar, trabalhar, fazer minha academia e ainda curtir quando me sobra tempo. (Allan)

Ainda encontra-se a avaliação realizada através de provas, trabalhos e exercícios, mas está aberta a possibilidade de consultar o material didático. A avaliação não é um “bicho de sete cabeças", pelo contrário, ela é vista com bons olhos pelos sujeitos da EJA: "O bom da EJA é que os professores facilitam bastante dando avaliação em dupla, com consulta, trabalhos" (Túlio, Tiago, Gustavo, Júlio, Ísis, Allan, Lucas, Leonardo). Eles também fazem sugestões do que consideram como formas mais fáceis ou eficientes de avaliação: "Gosto do método de ensino da EJA, mas prefiro trabalho" (Fabiana); "Sobre a avaliação, acho melhor trabalho, porque é melhor fazer com alguém pra ajudar a pensar e até fazer novas amizades" (Marisa); "Eu prefiro quando os professores fazem trabalho à prova” (Élcio, Graciele); “Não gosto de provas, prefiro trabalhos” (Douglas); "Eu não gosto de avaliação, pois para mim é como que tivesse que gravar tudo na cabeça" (Walter).

Mesmo que a avaliação implique em tensão no processo de aprendizagem, os depoimentos que seguem nos mostram que a atuação docente frente aos processos avaliativos, coloca-se como um diferencial, colaborando com os resultados dos estudantes. Muitos depoimentos mostram não apenas satisfação com as formas de avaliação utilizadas pelos professores, mas, também, a articulação feita pelos alunos entre o processo avaliativo e apreensão de conhecimentos ao longo da formação na EJA: "Eu aprendo mais na EJA do que no ensino regular" (Élcio); "Avaliação no Ensino Fundamental era mais complicada e no Ensino Médio, na EJA, é mais fácil, porque a maioria dos professores ajuda os alunos dando a opção de pesquisa no caderno" (Leonardo); "No ensino regular as provas são muito rígidas e difíceis, já na EJA aprendi a gostar das provas porque os professores ajudam bastante" (Tiago); "Eu não gostava do modo que eu era avaliado porque eles não faziam prova com consulta" (Gustavo).

As representações sobre a autoavaliação comparecem com mais força na representação da avaliação nos desenhos feitos por eles e em algumas frases que 
acompanhavam o desenho ${ }^{5}$. A ansiedade e o nervosismo em relação à avaliação estão muito mais associados a sentimentos pessoais que justificam o insucesso no processo, isto é, aparece com mais força uma autoavaliação, uma responsabilização de si pelo resultado: “Vem um branco na hora... será que estudei o necessário?” (Desenho 1). "Será que meu esforço valeu a pena?" (Desenho 3). Será preciso mais esforço meu para eu me dar bem" (Desenho 7). "Trabalho o dia inteiro e não tenho tempo para estudar, aí fico boiando" (Desenho 5).

Os ritos da avaliação também aparecem na representação de um relógio que indica o pouco tempo que é permitido para se resolver o que é solicitado (Desenho 9). 0 conflito entre o tempo do sujeito e o tempo do relógio; "Fico com o coração na mão" (Desenho 10); “Quem mandou não estudar?” (Desenho 14).

Os tipos de representações expressas nesses desenhos e falas anunciam o quanto esses jovens e adultos mergulham num poço de desejos: as boas notas e avaliações, o bom emprego, ser exemplo de vida, enfim, teorizando a seu modo sobre o curso das suas vidas, permeado de avanços e recuos, entrecortados pela escola, trabalho e vida pessoal, assim deixando orientações para se pensar o processo de ensinar e aprender e nele, o processo de avaliação.

\section{Alternativas de avaliações para a EJA}

Muitas vozes contribuem para as proposições a serem feitas aqui. Antes mesmo de pensar a avaliação, o professor precisa conhecer seus alunos, precisa tomar conhecimento do que eles já sabem e construir sua prática pedagógica com base nos saberes de seu aluno. O professor precisa entender que os sujeitos da EJA já possuem uma série de conhecimentos e crenças que devem ser relacionados com o que aprendem na escola, pois eles têm muito a contribuir.

\footnotetext{
${ }^{5}$ Como não colocaram nomes nos desenhos, aqui aparecerá apenas a numeração de cada um deles e não o nome fictício do autor.
} 
É notória a heterogeneidade das salas de aula da EJA. Há adolescentes, jovens e adultos, todos com muito a contribuir, cada um à sua maneira e com suas experiências. Nas observações feitas durante o processo desta pesquisa, os adultos sempre queriam contar suas experiências, por isso a importância de dar voz a esses alunos, que no passado foram tirados o direito ao estudo no ensino regular. E mais importante ainda é valorizar esta volta à escola e fazer com que este retorno e permanência sejam não apenas para receber um diploma, mas sim para construir novos valores e saberes. Além disso, a educação deve proporcionar aos sujeitos que a ela acessam o resgate de seus direitos, através da leitura de mundo e de saberes tecnológicos que os conduzirão ao exercício da sua cidadania e de uma profissão. Pensando nisso, é importante que cada professor, ao planejar sua aula, reflita sobre a importância de cada conteúdo ministrado para estes jovens e adultos.

Não basta o professor fazer uma avaliação diagnóstica, ou seja, conhecer o aluno e identificar seu conhecimento prévio e na terceira semana de aula aplicar uma prova que não estimule o pensar do aluno, nem tampouco valorize esse conhecimento prévio. É o que preconizam as Diretrizes Curriculares Nacionais para a EJA, definidas no Parecer 11/2000: "A EJA é momento significativo de reconstruir estas experiências da vida ativa e ressignificar conhecimentos de etapas anteriores da escolarização articulando-os com os saberes escolares" (BRASIL, 2000, p. 34).

Para a avaliação da EJA, é possível utilizar muitos recursos, como: exames orais, relatórios referentes a experimentos feitos, resenhas sobre filmes, relatórios de visitas técnicas, rodas de discussão, produções textuais, organização de pôsteres e sua apresentação e até mesmo a tão tradicional prova. Um dos alunos da EJA, sujeito desta pesquisa, também cita algumas formas de avaliação: “Eu prefiro um debate sobre a matéria ou um resumo, porque para resumir tenho que ler com atenção" (Allan).

Sordi (2009, p. 178) afirma que a diversificação didática auxilia os alunos a evidenciar de múltiplas maneiras o que aprenderam. A autora completa dizendo que o professor precisa utilizar sua criatividade para isso. Em uma das autobiografias, uma aluna pede essa diversificação: "Tem que focar em outras coisas também não só em prova, fazer coisas diferentes, tentar divertir um pouco as aulas" (Graciele). 
Sordi (2009, p. 179-180) traz uma lista de recursos que podem ser usados para avaliar um aluno: criar situações-problemas que estimulem a mobilização dos saberes trabalhados; conceber tarefas que requeiram do estudante o uso de habilidades cognitivas de alta complexidade para formular respostas; incentivar a produção de mini pesquisas; estimular experiências de autoavaliação; usar simulações de situação real para a análise e a emissão de parecer; desenvolver dispositivos de avaliação na forma de projetos que articulem várias disciplinas diferentes.

A mesma autora utiliza os verbos estimular, incentivar, desenvolver, analisar. Segundo ela, é preciso substituir os verbos conceituar, descrever e enumerar por analisar, interpretar e criticar. É preciso fazer com que o aluno interprete a questão e saiba responder de forma clara e coerente.

São vários os recursos para avaliar uma turma e a utilização de cada um deles dependerá da intenção do avaliador e deverá estar coerente com o público-alvo. A utilização da prova como um instrumento de avaliação, quando for o caso, precisa informar ao professor de que forma o aluno se apropriou do conhecimento transmitido por ele. A prova avalia tanto o trabalho do professor quanto do aluno. Por isso, precisa estar estruturada de forma que faça o aluno refletir sobre o conteúdo e o professor sobre sua prática.

Não basta apenas o professor entregar a prova com a nota baixa e não fazer nenhum comentário sobre o desempenho do aluno. Assim como afirma Sadler (1998 apud BOAS, 2012, p. 183):

Mesmo que o professor ofereça ao aluno observações válidas e/ou notas sobre o seu desempenho, o progresso nem sempre ocorre, porque ele necessita mais do que notas. Precisa conhecer os níveis de desempenho, objetivos ou evidências de aprendizagem que o professor espera dele para que possa comparar o que já aprendeu com o que ainda lhe falta aprender e engajar-se no processo apropriado. O feedback do professor aponta-lhe o que fazer para avançar. 
Segundo o autor, há relatos de resultados positivos de pesquisas com alunos de baixo rendimento e com dificuldades que, ao receberem feedback constantes, conseguiram melhoria considerável no processo de aprendizagem. Essas são características da avaliação formativa que promove o desenvolvimento não só do aluno, mas também do professor e da escola.

A avaliação formativa objetiva superar a avaliação unilateral, classificatória e punitiva, comprometendo-se com a aprendizagem e o sucesso de todos os alunos. Boas (2012) traz algumas questões que devem ser pensadas ao planejar uma avaliação:

Para que avaliar o grupo de alunos com quem vou trabalhar? As finalidades estão aliadas às características dos alunos. Quem são eles? Qual sua procedência? Qual sua faixa etária? Por que está nesta escola? Que experiências de aprendizagem possuem? Que expectativas apresentam? As respostas a essas e a outras indagações dão início à avaliação diagnóstica, imprescindível para o andamento adequado das atividades. (BOAS, 2012, p. 190)

E o autor continua:

Como implementar tais idéias? Em primeiro lugar, o "que fazer" e o "como fazer" devem brotar das escolas e não dos gabinetes do MEC e das secretarias de educação. Em segundo lugar, os recursos para a educação devem dirigir-se diretamente às escolas públicas, não devendo ser alocados em projetos elaborados por pessoas externas a elas. Em terceiro lugar, deve ser dada atenção especial à formação continuada dos profissionais da educação, para que se atinjam os dois primeiros itens. Essas são condições básicas para que a escola seja capaz de construir a proposta pedagógica que atenda às necessidades de formação do cidadão e do futuro trabalhador que possa ter inserção social crítica. (BOAS, 2012, p. 210)

As contribuições dessas pesquisas, relacionadas com as representações dos alunos sobre a forma como percebem a avaliação, colocam em pauta a urgente necessidade de dar outro rumo à forma como as avaliações vêm acontecendo no cotidiano do trabalho 
pedagógico, e é possível perceber que as avaliações da EJA, nas escolas pesquisadas, têm caminhado nessa direção.

\section{Considerações finais}

Por mais que o tema da avaliação tenha sido dissecado nas pesquisas em educação, a avaliação na EJA pouco ou quase nada tem aparecido entre as publicações acadêmicas. Isso anuncia alguns silenciamentos em relação aos processos extraescolares como condimentos que precisam ser considerados na avaliação da EJA. Esses sujeitos que aí chegam, chegam urdindo sonhos e temores. Vivem o difícil equilíbrio entre escola, emprego, desemprego, constituição de família, separação, redescoberta da juventude. Enfim, deparam-se com o futuro e com a vida adulta por diversas vias e alguns des-vios. $\mathrm{O}$ professor precisa conhecer a história de vida do seu aluno, sua trajetória escolar, o motivo por ter abandonado o ensino regular e retornar na EJA para, então, construir sua prática pedagógica e avaliativa. Sobretudo porque, na EJA, o professor se depara com alunos de quinze, dezesseis, vinte e seis, trinta e cinco, quarenta e oito ou sessenta anos sentados lado a lado, cada um com suas experiências e expectativas.

Por isso, ouvir as vozes dos sujeitos que constituem o universo da sala de aula fazse fundamental. Os depoimentos desses sujeitos, aqui apresentados, indicam caminhos da avaliação, sugerem estratégias com base no seu cotidiano de vida e trabalho, rejeitam as formas avaliativas em decorrência da história de tensões que elas sempre suscitaram, ao longo da sua trajetória escolar.

Os dados analisados apontam que as práticas de avaliação que acontecem na escola não se configuram como o grande problema. Os professores utilizam de recursos avaliativos como provas com e sem consulta, trabalhos individuais e em grupo que os estudantes até apreciam e chegam mesmo a elogiar como essas práticas acabam por auxiliá-los no processo de aprendizagem. O sentimento de nervosismo, ansiedade, 
angústia, medo ou até mesmo "ficar com o coração na mão" tem suas raízes mais profundas nos seus "labirintos de vidas e trajetórias ioiô ${ }^{6 "}$.

Esses sentimentos também vêm, via de regra, do passado (ensino regular), pois a maioria afirma que na EJA é “mais fácil”, já que os professores prontificam-se a auxiliá-los quando encontram dificuldades de compreensão nos enunciados das questões. É importante pensar quem são esses jovens e adultos que estão frequentando a EJA, conhecer seus sonhos, anseios e expectativas para, então, serem avaliados de uma forma que sobressaia a qualidade de cada um, defendendo assim a não homogeneização das diferenças.

\section{Referências}

ARROYO, Miguel. Currículo: território em disputa. 2.ed. Petrópolis, RJ: Vozes, 2011.

ARROYO, Miguel. Outros sujeitos, outras pedagogias. 2 ed. Petrópolis, RJ: Vozes, 2014.

BOAS, B.M.F.V. Avaliação formativa: em busca do desenvolvimento do aluno, do professor e da escola. In.: VEIGA, I.P.A; FONSECA, M.(Orgs) As dimensões do projeto político pedagógico: novos desafios para a escola. 9 ed. Campinas, SP: Papirus, 2012.

BRASIL. Ministério da Educação. Parecer CNE/CEB nº 11/2000 e Resolução CNE/CEB nº. 01/2000: institui as Diretrizes Curriculares Nacionais para a Educação de Jovens e Adultos. Brasília: MEC, 2000. Disponível em:

<http://portal.mec.gov.br/secad/arquivos/pdf/eja/legislacao/parecer_11_2000.pdf > Acesso em: 25 abr. 2014.

BRASIL. Ministério da educação. Secretaria de Educação Continuada, Alfabetização e diversidade. Documento nacional preparatório à VI Conferência Internacional de Educação de Adultos (VI CONFITEA). Brasília: MEC; Goiânia: FUNAPE/UFG, 2009

CARVALHO, Roseli Vaz. O estado da arte das pesquisas em educação de jovens e adultos na CAPES- período de 1987 - 2006. Cadernos de Pesquisa: Pensamento Educacional v.4, n.8, p. 117-130, 2009. Disponível em: <

http://universidadetuiuti.utp.br/Cadernos_de_Pesquisa/pdfs/cad_pesq8/7_estado_arte_c p8.pdf> Acesso em 27 set 2015.

\footnotetext{
${ }^{6}$ Termo emprestado de José Machado Pais, da obra "Ganchos tachos e biscates: jovens trabalho e futuro. Porto: Âmbar, 2005.
} 
FERNANDES, Tereza; VIANA, Tania. Alunos com necessidades educacionais especiais (NEEs): avaliar para o desenvolvimento pleno de suas capacidades. Estudos em Avaliação Educacional, São Paulo, v.20, n.43, maio/ago. 2009. Disponível em: <http://www.fcc.org.br/pesquisa/publicacoes/eae/arquivos/1495/1495.pdf >. Acesso em 13 nov. 2013.

FERREIRA, Norma S. As pesquisas denominadas "estado da arte". Educação \& Sociedade, ano XXIII, n. 79, p.257-272, ago. 2002.

FRANCO, Maria Laura. Análise do conteúdo. Brasília: Plano: 2003.

FREIRE, Paulo. Pedagogia da autonomia: saberes necessários à prática educativa. São Paulo: Paz e Terra, 1999.

HADDAD, Sérgio.(Coord.) O estado da arte das pesquisas em educação de jovens e adultos no Brasil: a produção discente da pós-graduação em educação no período 1986 1998. São Paulo: Ação educativa, 2000.

LAFFIN, Maria Hermínia. Pesquisas no campo da educação de jovens e adultos (EJA) no e do Estado de Santa Catarina. Disponível em: <xanpedsul.faed.udesc.br/arq_pdf/6580.pdf>. 2014. Acesso em: 23 mar. de 2015.

MINAYO, Cecília de Souza. O conceito de Representações Sociais dentro da sociologia clássica. In: GUARESCHI, Pedrinho A.; JOVCHELOVITCH, Sandra (Orgs.) Textos em representações sociais. 10. ed. Petrópolis, RJ.. Vozes, 2008. p.89-111.

OLIVEIRA, Ivanilde; DIAS, Alder; MOTA NETO, João Colares da. Pesquisas em educação de Jovens e adultos no Brasil: a presença de Paulo Freire. 2012. Disponível em: <http://35reuniao.anped.org.br/trabalhos/127-gt18>. Acesso em: 02 set. 2013.

OLIVEIRA, Marta Kohl de. Jovens e adultos como sujeitos de conhecimento e aprendizagem. Revista Brasileira de Educação, n.12, set/out/nov/dez, 1999.

RIAL, Adriana Cristina. Avaliação da aprendizagem na educação de jovens e adultos - EJA: exame preliminar de produção acadêmica sobre a temática. In: REUNIÃO ANUAL DA ASSOCIAÇÃO NACIONAL DE PÓS-GRADUAÇÃO E PESQUISA EM EDUCAÇÃO, 30, Caxambu, MG, 7 a 10 de out. de 2007. Posters GT18: Educação de pessoas jovens e adultas 2007. Disponível em: <http://3oreuniao.anped.org.br/posteres/GT18-2794lnt.pdf>, Acesso em 27 set. 2015.

RIBEIRO, Márcio. Avaliação na educação de jovens e adultos: uma visão transformadora. Rio de Janeiro, 2002. 
SORDI, Mara. Alternativas propositivas no campo da avaliação: por que não? In: CASTANHO, Sérgio; CASTANHO, Maria Eugênia (Orgs). Temas e textos em metodologia do ensino superior. São Paulo: Papirus, 2001.p.171-182.

SORDI, Mara. Por uma aprendizagem "maiúscula” da avaliação da aprendizagem. In: DALBEN, Angela et al. (Orgs.) Convergências e tensões no campo da formação e do trabalho. Belo Horizonte: Autêntica, 2010.

VIANA, Danielle. $O$ estado do conhecimento da produção científica sobre a educação profissional integrada à educação de jovens e adultos no âmbito do projeto 008/PROEJA/CAPES/SETEC (2007 - 2011). 2012. 123 F. Dissertação (Mestrado em Educação Tecnológica) - Centro Federal de Educação Tecnológica de Minas Gerais (CEFET-MG). Belo Horizonte, 2012. 